\title{
Functional coating of liposomes using a folate- polymer conjugate to target folate receptors
}

\author{
This article was published in the following Dove Press journal: \\ International Journal of Nanomedicine \\ 12 July 2012 \\ Number of times this article has been viewed
}

\author{
Kazuo Watanabe \\ Makoto Kaneko \\ Yoshie Maitani \\ Institute of Medical Chemistry, Hoshi \\ University, Tokyo, Japan
}

\begin{abstract}
Folate-polymer-coated liposomes were developed for targeted chemotherapy using doxorubicin (DXR) as a model drug. Folate-poly(L-lysine) (F-PLL) conjugates with a folate modification degree of $16.7 \mathrm{~mol} \%$ on epsilon amino groups of PLL were synthesized. DXR-loaded anionic liposomes were coated with F-PLL, and the cellular association of F-PLL-coated liposomes was evaluated by flow cytometry, and confocal microscopy in human nasopharyngeal carcinoma KB cells overexpressing folate receptors (FRs), and human lung adenocarcinoma A549 cells [FR (-)]. The existence of a polymer layer on the surface of F-PLL-coated liposomes was confirmed by zeta potential analysis. The KB cellular association of F-PLL-coated liposomal DXR was increased compared with that of PLL-coated liposomes and was inhibited in the presence of free folic acid. Twofold higher cytotoxicity of F-PLL-coated liposomal DXR was observed compared with that of the PLL-coated liposomal DXR in KB cells, but not in A549 cells, suggesting the presence of FR-mediated endocytosis. These results indicated that folate-targeted liposomes were prepared successfully by coating the folate-polymer conjugate F-PLL. This novel preparation method of folate-targeted liposomes is expected to provide a powerful tool for the development of a folate-targeting drug nanodevice as coating with ligand-polymer conjugates can be applicable to many kinds of particles, as well as to lipid-based particles.
\end{abstract}

Keywords: cellular association, folate-targeting, liposome, poly-L-lysine, polymer coating, tumor targeting

The tumor-targeting abilities of anticancer drugs is important in chemotherapy as accuracy reduces serious side effects for patients, as anticancer drugs tend to distribute throughout the whole body and can cause cytotoxicity. In drug-delivery systems (DDSs), folic acid (FA) is used as a tumor-targeting ligand, which leads nanoparticles into cancer cells as a result of folate-receptor (FR)-mediated endocytosis, because FRs are overexpressed in many human cancer cells, while they show limited expression in normal cells. ${ }^{1-6}$ When folate is covalently linked to a molecule and a particle, its affinity for its cell surface receptor $\left(\mathrm{Kd}\right.$ of approximately $\left.10^{-9} \mathrm{M}\right)$ remains essentially unaltered. Therefore, folate modification has been employed for various nanoparticles. In these cases, particles were formed by folate-conjugated polymers alone ${ }^{7-13}$ or preformed particles were conjugated to folate polymers. ${ }^{14}$ In particular, liposomes have been modified in many cases, including in previous reports by the present authors, using folate-polyethylene glycol (PEG)-lipid. ${ }^{15-19}$

Liposomes are widely used as drug carriers because they can entrap hydrophilic and hydrophobic drugs and can be easily surface-modified with folate-PEG-lipids. For the 
tumor targeting of folate-PEG-modified liposomes in vivo, proper PEGylation is also needed, because the initial (and overall) tumor accumulation is still based on passive extravasation. ${ }^{18}$ PEGylated liposomes exhibit a prolonged circulation in the blood $^{20-22}$ and eventually accumulate into tumors via the enhanced permeability and retention (EPR) effect. ${ }^{23-25}$ However, cellular association of PEGylated liposome was decreased because of the steric hindrance between the cell surface and PEG chains on the liposome. ${ }^{26}$ Furthermore, the accelerated blood clearance (ABC) phenomena of PEGylated liposomes were reported following repeated injections of PEGylated liposomes. ${ }^{27,28}$ In these cases, it is known that the linker part of PEG-lipids may be recognized by an antibody. ${ }^{29,30}$ In order to resolve these problems, new techniques to prepare folate-targeted liposomes are required that do not involve the use of PEG-lipids.

Several investigations regarding polymer-coated liposomes have been carried out relating to intravenous administration. The major reasons for the inclusion of polymer coatings on the surface of liposomes are the prolonged circulation in the blood compared to when PEG-lipids are used, the sustained release of drugs from the liposomes, and the stabilization of the liposome structure. ${ }^{31-33}$ To the best of our knowledge, folate-targeted liposomes coated with folatepolymer conjugates have not been reported previously.

In the present study, we explored the potential use of a novel conjugate, folate-poly(L-lysine) (F-PLL), by coating anionic liposomes using ionic interactions as a tumortargeting device for injection with doxorubicin (DXR) as a model drug. We characterized F-PLL-coated liposomes by measuring cellular association using flow cytometry and confocal microscopy, and the cytotoxicity of the liposomal drug in human nasopharyngeal carcinoma $\mathrm{KB}$ cells overexpressing FR $[\mathrm{FR}(+)]$ and FR-negative human lung adenocarcinoma A549 cells [FR (-)]. The novel preparation method of a folate-targeted nanodevice was also investigated.

\section{Methods \\ Materials}

PLL $(\mathrm{Mw}=30,000-70,000)$, sodium cholesteryl sulfate $\left(\mathrm{Ch}-\mathrm{SO}_{4}\right)$, and deuterium oxide $\left(\mathrm{D}_{2} \mathrm{O}\right)$ were purchased from Sigma-Aldrich Corporation (St Louis, MO). FA, cholesterol $(\mathrm{Ch})$, triethylamine, and DXR hydrochloride were obtained from Wako Pure Chemical Industries (Osaka, Japan). Hydrogenated soybean phosphatidylcholine (HSPC) was obtained from the NOF Corporation (Tokyo, Japan). 1-Ethyl-3-(3-dimethylaminopropyl)carbodiimide (EDC, liquid form) was purchased from Fluka Chemical Company (Buchs, Switzerland). Folate-deficient RPMI-1640 medium, fetal bovine serum (FBS), and 1,1'-dioctadecyl-3,3,3',3'tetramethylindocarbocyanine perchlorate (DiI) were purchased from the Invitrogen Corporation (Carlsbad, CA). Spectra/Por CE membranes (MWCO 2000 Da) were purchased from Spectrum Laboratories Inc (Rancho Dominguez, CA). Other reagents used were of reagent grade.

\section{Synthesis of the F-PLL conjugate}

The scheme of F-PLL conjugate synthesis is illustrated in Figure 1. FA ( $86 \mathrm{mg}, 195 \mu \mathrm{mol})$ was dissolved in $1.5 \mathrm{~mL}$ of water, and then $80 \mu \mathrm{L}$ of liquid EDC (450 $\mu \mathrm{mol})$ was added and stirred for 1 hour at room temperature, as described in previous studies, with a minor modification. ${ }^{34}$ PLL (50 mg, $390 \mu \mathrm{mol})$ was dissolved in $1 \mathrm{~mL}$ of water, and then $60 \mu \mathrm{L}$ of triethylamine $(430 \mu \mathrm{mol})$ was added. The activated FA and PLL were mixed and stirred for 4 hours at room temperature. The resulting mixture was dialyzed against distilled water for 2 days in order to remove free FA. After dialysis, $200 \mu \mathrm{L}$ of $1 \mathrm{~N} \mathrm{HCl}$ was added to the solution in which the product was dissolved. The acidic suspension was centrifuged at $15,000 \mathrm{rpm}$ for 10 minutes in cold conditions. After centrifugation, the precipitate containing a urea derivative derived from EDC was removed. The supernatant containing the product was dialyzed against distilled water, again for 2 days, and then lyophilized for 24 hours at $-80^{\circ} \mathrm{C}$. When the mole proportion of the mixed FA against the epsilon amino groups of PLL was $50 \mathrm{~mol} \%$ and $30 \mathrm{~mol} \%$, the products were named F-PLL and low F-PLL, respectively. Yields of the products were $96 \%$ for F-PLL and 62\% for low F-PLL.

\section{'H NMR study}

The covalent bonding between FA and PLL was ascertained using a VARIAN 400-MHz ${ }^{1} \mathrm{H}$ NMR spectrometer (Varian Inc, Palo Alto, CA) with tetramethylsilane as the reference. The lyophilized product was dissolved directly in $\mathrm{D}_{2} \mathrm{O}$. FA and PLL were also dissolved in $\mathrm{D}_{2} \mathrm{O}$. The production of new bonds was evaluated by the chemical shift of $2 \mathrm{H}$ protons of lysine in the range of 3.17-2.88 ppm.

\section{Evaluation of folate modification degree on PLL}

The extent of folate modification against the amino group of PLL was examined by spectrophotometry. Lyophilized F-PLL conjugates were dissolved in water. The UV spectrum of the F-PLL solution was obtained using a Shimadzu UV-1700 spectrophotometer (Shimadzu Corporation, Kyoto, Japan). The content of FA and PLL in the F-PLL aqueous solution was determined using calibration curves at $363 \mathrm{~nm}$ 


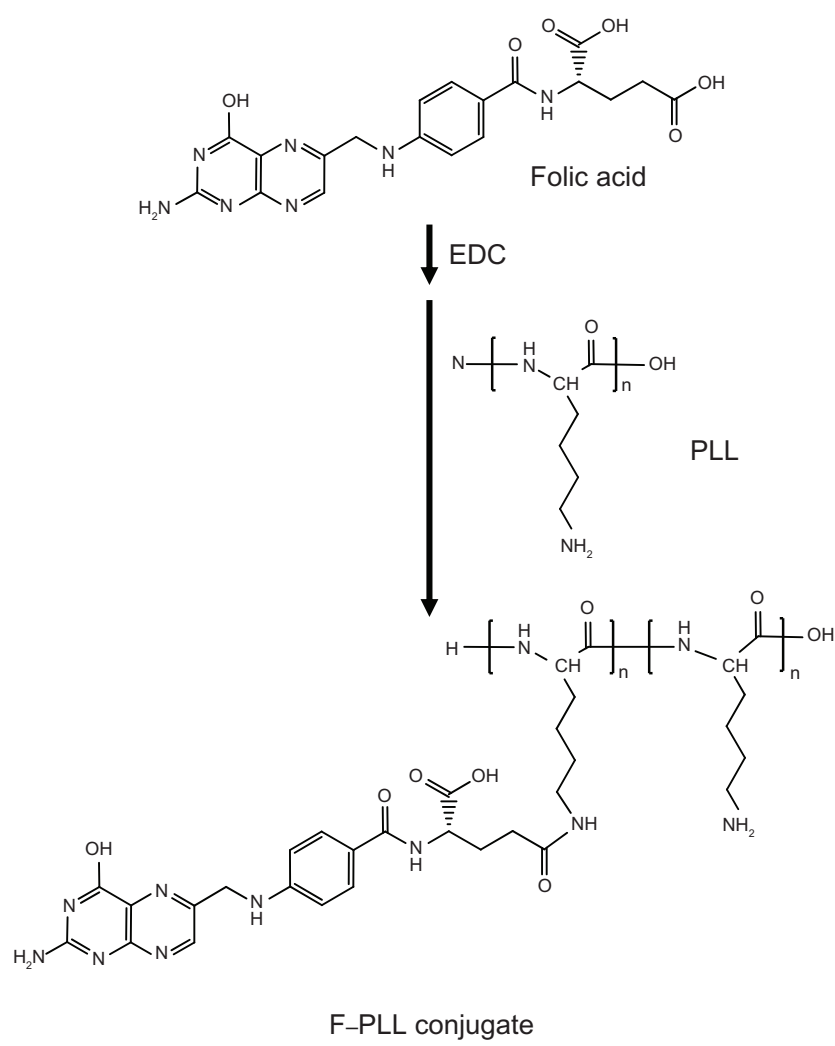

Figure I Schematic illustration of F-PLL conjugate synthesis.

Abbreviations: EDC, I-ethyl-3-(3-dimethylaminopropyl)carbodiimide; F-PLL, folatepoly(L-lysine).

and $215 \mathrm{~nm}$, respectively. The absorbance of F-PLL at $363 \mathrm{~nm}\left(\mathrm{~A}_{\mathrm{F}-\mathrm{PLL}}^{363}\right)$ was equal to that of FA $\left(\mathrm{A}_{\mathrm{FA}}^{363}\right)$ because the UV absorption of PLL was detected only below $240 \mathrm{~nm}$; $\mathrm{A}_{\mathrm{F}-\mathrm{PLL}}^{363}=\mathrm{A}_{\mathrm{FA}}^{363}$. We assumed that an additive property was held between the absorbance of FA $\left(\mathrm{A}_{\mathrm{FA}}^{215}\right)$ and PLL $\left(\mathrm{A}_{\text {PLL }}^{215}\right)$ at $215 \mathrm{~nm} ; \mathrm{A}_{\mathrm{F}-\mathrm{PLL}}^{215}=\mathrm{A}_{\mathrm{FA}}^{215}+\mathrm{A}_{\mathrm{PLL}}^{215}$.

\section{Preparation of liposomal DXR}

The composition of anionic liposomes was $\mathrm{HSPC} / \mathrm{Ch} /$ $\mathrm{Ch}-\mathrm{SO}_{4}=5 / 4 / 1(\mathrm{~mol} / \mathrm{mol} / \mathrm{mol})$. Liposomes were prepared with a thin lipid-film method. Briefly, HSPC (40 mg, $51 \mu \mathrm{mol}), \mathrm{Ch}(15 \mathrm{mg}, 39 \mu \mathrm{mol})$, and $\mathrm{Ch}-\mathrm{SO}_{4}(5 \mathrm{mg}, 10 \mu \mathrm{mol})$ were dissolved in chloroform. The solvent in the mixture was removed with the use of an evaporator to leave a thin lipid film. The lipid film was hydrated with $3 \mathrm{~mL}$ of citrate buffer ( $300 \mathrm{mM}$, adjusted to $\mathrm{pH} 4.0$ with $\mathrm{NaOH}$ ) at $60^{\circ} \mathrm{C}$ by vortex mixing and sonication. The liposomes were loaded with DXR via a $\mathrm{pH}$ gradient method (drug/lipid $=1: 5 \mathrm{w} / \mathrm{w}) .{ }^{18}$ DXR-loading efficiency ( $>96 \%$ ) was determined by separating unencapsulated drug from encapsulated drug using a Sephadex G-50 column (GE Healthcare UK Ltd, Buckinghamshire, UK). DXR concentration was analyzed using a fluorophotometer (Wallac 1420 ARVOsx multilabel counter; Perkin-Elmer Life Science, Waltham, MA) with excitation and emission wavelengths of $485 \mathrm{~nm}$ and $535 \mathrm{~nm}$, respectively. The particle size and zeta-potential of the prepared liposome were measured in water at $25^{\circ} \mathrm{C}$ using a Photal ELS-Z2 zeta-potential and particle size analyzer (Otsuka Electronics Co, Ltd, Osaka, Japan). DiI-labeled liposomes were also prepared by the addition of $0.04 \mathrm{~mol} \%$ DiI against total lipid moles when lipids were dissolved in chloroform for liposome preparation.

\section{Preparation of F-PLL conjugate-coated liposomes labeled with Dil and liposomal DXR}

A total of $500 \mu \mathrm{L}$ of $6.66 \mathrm{mg}$ total lipid/mL DiI-labeled liposome suspension or liposomal DXR suspension was placed in a test tube. The same volume of $1 \mathrm{mg} / \mathrm{mL}$ F-PLL or low F-PLL aqueous solution was added to the liposome suspension. The mixture was agitated by a vortex mixer and then was allowed to stand for 15 minutes at room temperature. Then, the suspensions were sonicated to reduce the size to about $120 \mathrm{~nm}$. To determine the quantity of unattached F-PLL and low F-PLL, the supernatants were removed after centrifugation, and absorbance was measured at $290 \mathrm{~nm}$. Approximately $10 \%$ of added F-PLL and low F-PLL remained in the removed supernatants of the centrifuged mixtures.

F-PLL-coated liposomal DXR was purified by centrifugation at $5000 \times \mathrm{g}$ for 2 minutes using centrifugal filter units, Amicon Ultra $100 \mathrm{~K}$ (Millipore Co, Billerica, MA), three times in cold conditions. Free DXR was removed completely by this filtration treatment. The DXR concentration of F-PLL and PLL-coated liposomal DXR was determined by measuring the absorbance at $480 \mathrm{~nm}$ (UV-1700 PhamaSpec; Shimadzu).

\section{Cell culture}

KB cells were obtained from the Cell Resource Center for Biomedical Research, Tohoku University (Miyagi, Japan). A549 cells [FR (-)] were kindly provided by OncoTherapy Science (Tokyo, Japan). The cells were cultured in folate-deficient RPMI-1640 medium containing 10\% heat-inactivated FBS and $50 \mu \mathrm{g} / \mathrm{mL}$ kanamycin sulfate in a humidified atmosphere of $5 \% \mathrm{CO}_{2}$ at $37^{\circ} \mathrm{C}$.

\section{Flow cytometry analysis}

$\mathrm{KB}$ cells and A549 cells were prepared by seeding $3 \times 10^{5}$ cells/well in a 6 -well plate $(2 \mathrm{~mL}$ culture medium/well) 1 day before the assay. The cells were incubated with F-PLL- and low F-PLL-coated liposome labeled with DiI, and F-PLL-coated liposomal DXR as $20 \mu \mathrm{g}$ DXR/mL 
for 1 hour or 3 hours at $37^{\circ} \mathrm{C}$. In free-folate competition studies, $5 \mathrm{mM}$ FA was added to the culture medium 2 hours before the assay. After incubation, cells were washed three times with cold phosphate-buffered saline (PBS; $\mathrm{pH} 7.4$ ) to remove unbound liposomes, detached with $0.02 \%$ EDTA in PBS for KB cells and with $0.05 \%$ trypsin in PBS for A549 cells, and then suspended in PBS containing $0.1 \%$ bovine serum albumin and $1 \mathrm{mM}$ EDTA. The suspended cells were directly introduced to a FACSCalibur flow cytometer (Becton Dickinson, San Jose, CA) equipped with a $488 \mathrm{~nm}$ argon ion laser. Data for 10,000 fluorescent events were obtained by recording forward scatter, side scatter, and $585 / 42 \mathrm{~nm}$ fluorescence. The autofluorescence of the cells incubated without F-PLL-coated liposomal DXR was taken as a control.

\section{Confocal microscopy study}

$\mathrm{KB}$ cells and A549 cells were prepared by seeding $3 \times 10^{5}$ cells/well on a $35 \mathrm{~mm}$ diameter glass dish 1 day before the assay. The sample preparation procedures were the same as those for flow cytometry. After a 3-hour incubation of the cells with F-PLL-coated liposomal DXR, the cells were washed twice with cold PBS ( $\mathrm{pH} 7.4$ ). Then, the cells were fixed with $10 \%$ formaldehyde in $\mathrm{PBS}$ at $37^{\circ} \mathrm{C}$ for 15 minutes. The fixed cells were washed twice again with PBS in order to remove surplus formaldehyde. The washed samples were coated with Aqua Poly/Mount (Polyscience Inc, Warrington, PA) and then covered with a cover glass. Cells incubated with the F-PLL-coated liposomal DXR were observed with the use of a Carl Zeiss LSM 5 EXCITER confocal laser scanning microscope (Carl Zeiss MicroImaging Co, Ltd, Göttingen, Germany). Maximum excitation was done with the 488-nm line of an argon laser and fluorescence emission was observed at $>570 \mathrm{~nm}$ (using 560DCLP and E570LP filters).

\section{Cytotoxicity study}

Briefly, $1 \times 10^{4}$ cells were plated into 96-well culture plates 1 day before the experiment. KB cells and A549 cells were incubated with free or liposomal DXR containing 0.01 to $100 \mu \mathrm{g} / \mathrm{mL}$ DXR diluted in $100 \mu \mathrm{L}$ FA-free medium for 2 hours at $37^{\circ} \mathrm{C}$. After incubation, the cells were washed with cold PBS (pH 7.4) and cultured in fresh medium for a further 48 hours. Then, $10 \mu \mathrm{L}$ WST-8 (Cell Counting Kit-8; Dojindo Laboratories, Kumamoto, Japan) stock solution ( $5 \mathrm{mM}$ ) was added to each well, and the plate was incubated for 1 hour at $37^{\circ} \mathrm{C}$. Cell viability was assessed by measuring the absorbance at $450 \mathrm{~nm}$.

\section{Statistical analysis}

The statistical significance of the data was evaluated by Student's $t$-test. $P<0.05$ was considered significant.

\section{Results and discussion Synthesis and characterization of F-PLL conjugates}

Two different folate modifications in F-PLL conjugates were synthesized with carbodiimide coupling chemistry (Figure 1). The gamma carboxyl group of FA is mainly activated by carbodiimide and combined with an amino group of PLL. ${ }^{35}$ The prepared F-PLL conjugates containing the free alpha carboxyl group of the FA should be an effective pilot molecule for the accumulation of nanoparticles in KB cells caused by FR-mediated endocytosis, because only the alpha carboxyl group of the FA is recognized by FRs on KB cells. ${ }^{35}$

Conjugation with FA was confirmed by the ${ }^{1} \mathrm{H}$ NMR spectrometer. Figure 2 shows the ${ }^{1} \mathrm{H}$ NMR spectra of PLL, FA, and the F-PLL conjugate. The chemical shift of protons combined with the epsilon carbons of PLL appeared at approximately 3 ppm, whereas no chemical shift of FA was observed at around $3 \mathrm{ppm}$. In the NMR peak of F-PLL conjugates, the protons combined with the epsilon carbons of PLL were shifted downfield (2.9 ppm) and a new peak appeared at around $3.2 \mathrm{ppm}$. The new peak may be associated with amide bond production between the epsilon amino group of PLL and the gamma carboxyl group of FA.

The extent of folate modification in F-PLL conjugates was determined by UV analysis (Supplementary Figure S1). The degrees of folate modification in F-PLL conjugates were calculated: the molar ratio of $\mathrm{FA} / \mathrm{NH}_{2}$ in $\mathrm{F}-\mathrm{PLL}$ and low F-PLL was $16.7 \mathrm{~mol} \%$ and $9.5 \mathrm{~mol} \%$, respectively. About one-third of the added free FA was combined with PLL via the coupling reaction in the present experiment. The quantity of the unattached F-PLL conjugate against the anionic liposome was determined by photometry. About $10 \%$ of the added F-PLL remained in the solution without adsorption on to the liposome surface. Therefore, the mole percent of folate on liposome against total lipids was $6.9 \mathrm{~mol} \%$ for F-PLL-coated liposomes and $4.5 \mathrm{~mol} \%$ for low F-PLL-coated liposomes.

\section{Physicochemical properties of F-PLL- coated liposomal DXR}

The mean particle size, polydispersity index (PDI), and zetapotential of F-PLL-coated and PLL-coated liposomal DXR are given in Table 1. The coated liposomes had an average particle size of $120 \mathrm{~nm}$ with a narrow size distribution (low PDI values). 
A

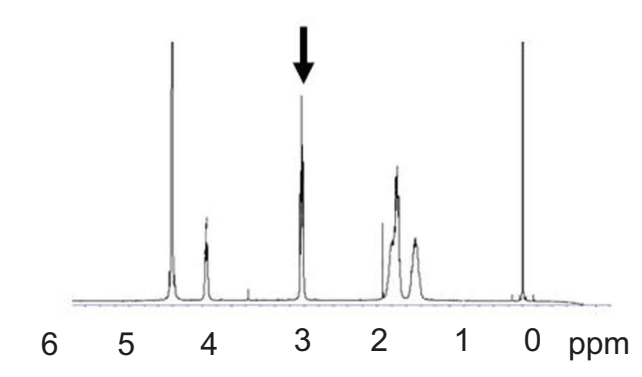

B

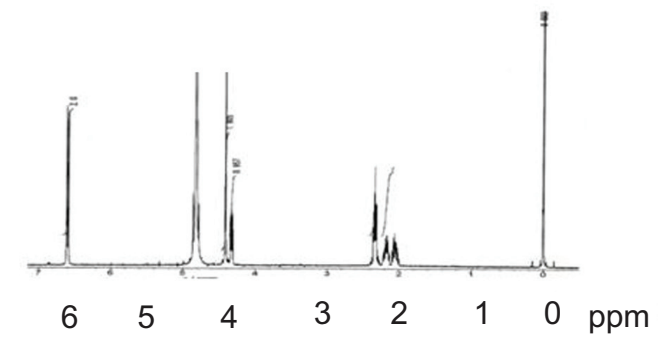

C

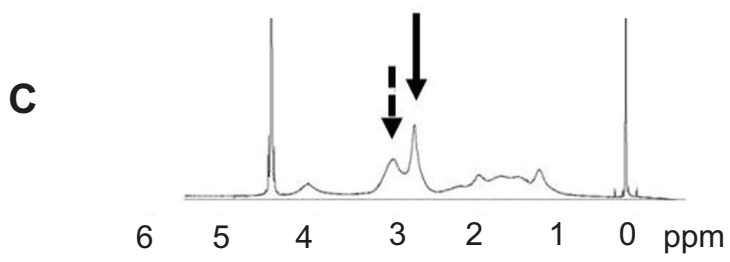

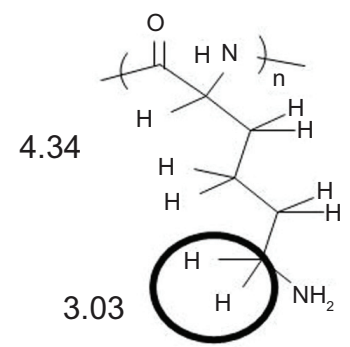

$1.47-1.74$

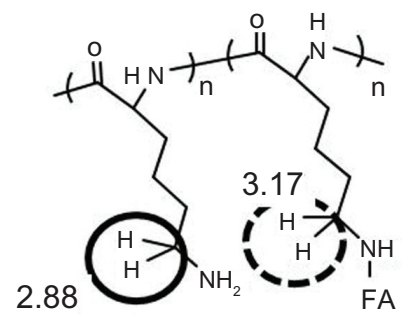

Figure 2 'H NMR spectra of (A) PLL, (B) FA, and (C) F-PLL.

Abbreviations: FA, folic acid; F-PLL, folate-poly(L-lysine); ppm, parts per million.

The liposomes may be coated with PLL and F-PLL because the PLL- and F-PLL-coating changed a negatively charged zeta-potential $(-55.4 \pm 5.7 \mathrm{mV})$ to a positively charged zetapotential for the coated liposomes $(46.8 \pm 1.3 \mathrm{mV}$ and $34.1 \pm$ $1.9 \mathrm{mV}$, respectively), without a large change in the particle size $(115-119 \mathrm{~nm})$. An electrostatic interaction between the sulfonate residue of $\mathrm{Ch}-\mathrm{SO}_{4}$ in the liposomes and the free amino groups on PLL and F-PLL may occur.

\section{Cellular association of F-PLL-coated liposomes}

First, the effect of the degree of folate modification of F-PLL conjugates on cellular association was examined. Figure 3 shows the results of cellular association of F-PLLcoated and low F-PLL-coated liposomes, corresponding with liposomes coated with F-PLL conjugates with a folate modification of $6.9 \mathrm{~mol} \%$ and $4.5 \mathrm{~mol} \%$, respectively. The fluorescence intensity of F-PLL-coated DiI-labeled liposomes incubated with $\mathrm{KB}$ cells for 1 hour at $37^{\circ} \mathrm{C}$ was shifted toward the right, depending on the increase in the folate-modification degree on the liposomes. The mean fluorescence intensity of F-PLL-coated DiI-labeled liposomes was 1.5-fold higher than that of low F-PLL-coated liposomes, corresponding well with an approximately 1.5 -fold higher level of folate modification of PLLs. As a consequence of this finding, higher folate-modified F-PLL-coated liposomes were used in the following experiments.

Next, in order to examine the mechanism of the cellular association, inhibition of the cellular association of PLLcoated and F-PLL-coated liposomal DXR due to the presence of FA in the medium was examined by flow cytometry and confocal laser scanning microscopy. Flow cytometry results showed that $\mathrm{KB}[\mathrm{FR}(+)]$ cellular association of F-PLL-coated liposomes was higher than that of PLL-coated liposomes after a 3-hour incubation at $37^{\circ} \mathrm{C}$ (Figure $4 \mathrm{~A}$ ). This cellular association of F-PLL-coated liposomes was suppressed significantly by the addition of $5 \mathrm{mM}$ FA to the culture medium. In order to confirm the cellular uptake of F-PLL-

Table I Physicochemical properties of prepared liposomal DXR

\begin{tabular}{llll}
\hline Liposome & $\begin{array}{l}\text { Particle } \\
\text { size }(\mathbf{n m})\end{array}$ & PDI & $\begin{array}{l}\text { Zeta potential } \\
(\mathbf{m V})\end{array}$ \\
\hline $\begin{array}{l}\text { Liposomal } \\
\text { DXR }\end{array}$ & $\mathrm{I} 15.3 \pm 10.0$ & $0.225 \pm 0.014$ & $-55.4 \pm 5.7$ \\
$\begin{array}{l}\text { F-PLL-coated } \\
\text { liposomal DXR }\end{array}$ & $\mathrm{I} 17.4 \pm 2.2$ & $0.180 \pm 0.015$ & $34.1 \pm 1.9$ \\
$\begin{array}{l}\text { PLL-coated } \\
\text { liposomal DXR }\end{array}$ & $\mathrm{I} 19.7 \pm 2.1$ & $0.192 \pm 0.009$ & $46.8 \pm 1.3$ \\
\hline
\end{tabular}

Notes: Each value represents the mean $\pm S D ;{ }^{a} n=4 ;{ }^{b} n=3$.

Abbreviations: DXR, doxorubicin; F-PLL, folate-poly(L-lysine); PDI, polydispersity index. 


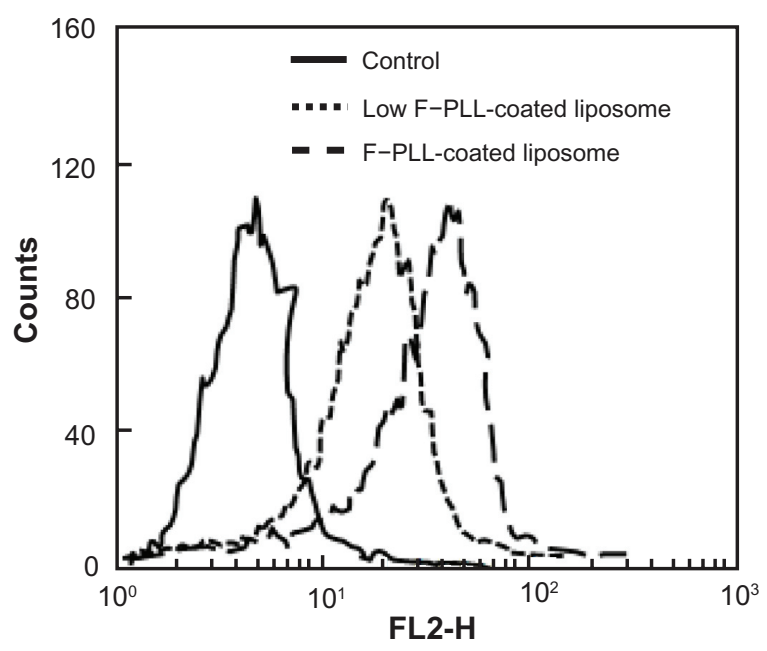

Figure 3 Cellular association of F-PLL or low F-PLL-coated liposomes labeled with Dil in KB cells analyzed by flow cytometry after a I-hour incubation.

Notes: The control indicates the autofluorescence of untreated cells. Each analysis was generated by counting $10^{4}$ cells.

Abbreviations: Dil, I,I'-dioctadecyl-3,3,3',3'-tetramethylindocarbocyanine perchlorate; F-PLL, folate-poly(L-lysine).

coated liposomes via FRs, A549 cells [FR (-)] were used as a negative control. As shown in Figure 4B, A549 cellular association of PLL- and F-PLL-coated liposomes was quite low, as indicated by the mean fluorescence intensity of DXR. In order to investigate $\mathrm{KB}$ cellular adsorption of F-PLLcoated liposomal DXR, their cellular association at $4^{\circ} \mathrm{C}$ was examined after a 3-hour incubation (Figure 4C). The cellular association of liposomal DXR was very low irrespective of the addition of $5 \mathrm{mM}$ FA to the culture medium. Although $\mathrm{KB}$ cellular association of PLL-coated liposomes was lower than that of F-PLL-coated liposomes at $37^{\circ} \mathrm{C}$, it was more than half of the cellular-association level of F-PLL-coated liposomes (Figure 4A). The effect may be caused by the nonselective adsorption of PLL-coated liposomal DXR onto the cell surface because PLL-coated liposomal DXR was positively charged (Table 1). These findings indicate that the mechanism of cellular association of F-PLL-coated liposomal DXR in KB cells is FR-mediated endocytosis.
Furthermore, in order to confirm the cellular uptake of the particles as shown in Figure 4, KB cells incubated with F-PLL-coated liposomal DXR for 3 hours were observed by confocal laser scanning microscopy. In the absence of FA in the culture medium, the adsorption of F-PLL-coated liposomal DXR on the cell surface was not observed, and most fluorescent particles were observed inside the nucleus, indicating cellular uptake (Figure 5A). In the presence of FA, few fluorescent particles were observed inside the cells, indicating the inhibition of cellular uptake by FA (Figure 5B). The cellular association of F-PLL-coated liposomal DXR in A549 cells with or without FA was hardly observed (Supplementary Figure S2).

\section{Cytotoxicity of F-PLL-coated liposomal DXR}

To confirm the cellular uptake of the liposomes, the cytotoxicity of F-PLL-coated and PLL-coated liposomal DXR was examined (Figure 6). Cytotoxicity of F-PLL-coated liposomal DXR $\left(\mathrm{IC}_{50}=30.75 \mu \mathrm{M}\right)$ in $\mathrm{KB}$ cells was approximately twofold higher than that of PLL-coated liposomal DXR $\left(\mathrm{IC}_{50}=64.97 \mu \mathrm{M}\right)$, as shown in Table 2. On the other hand, the cytotoxicity of F-PLL-coated liposomal DXR $\left(\mathrm{IC}_{50}=104.31 \mu \mathrm{M}\right)$ in A549 cells was low and similar to that of PLL-coated liposomal DXR $\left(\mathrm{IC}_{50}=105.71 \mu \mathrm{M}\right)$. These findings corresponded with the cellular-association data and confocal laser scanning microscopic observations, as shown in Figures 4 and 5, indicating that the cellular association of F-PLL-coated liposomes into KB cells is via an FR-mediated pathway.

\section{Comparison of cellular uptake of F-PLL- coated liposomes with folate-PEG modified particles}

A combination of PEG linker length, folate-modification density, liposome surface charge, and liposome composition governs the receptor affinity of folate-targeted liposomes in vitro. Interestingly, in this study, although the
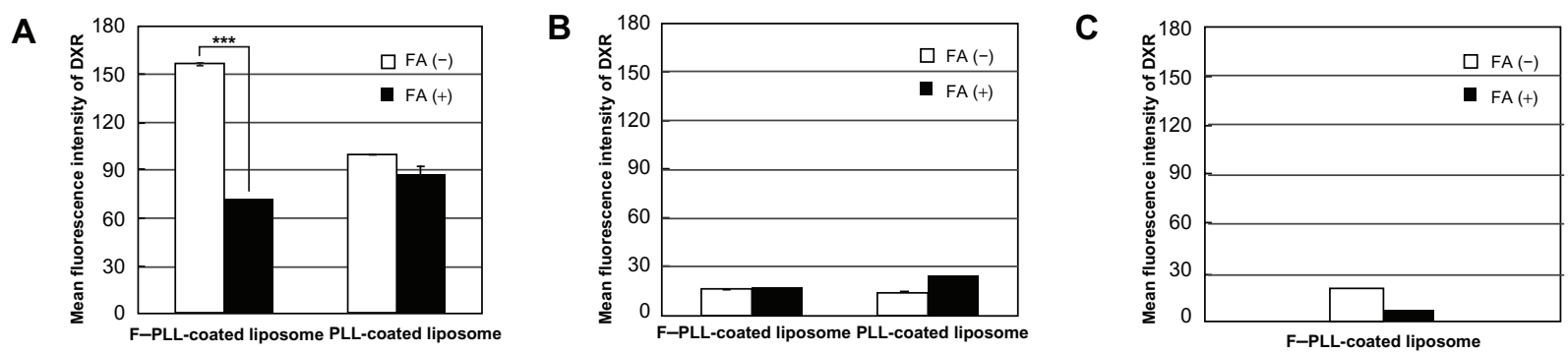

Figure 4 Cellular association of PLL- or F-PLL-coated liposomal DXR in (A) KB cells and in (B) A549 cells incubated at $37^{\circ} \mathrm{C}$, and in (C) $\mathrm{KB}$ cells incubated at $4^{\circ} \mathrm{C}$ for 3 hours with or without 5 mM FA analyzed by flow cytometry.

Note: Each value represents the mean \pm SD $(n=3)$.

Abbreviations: DXR, doxorubicin; FA, folic acid; F-PLL, folate-poly(L-lysine). 

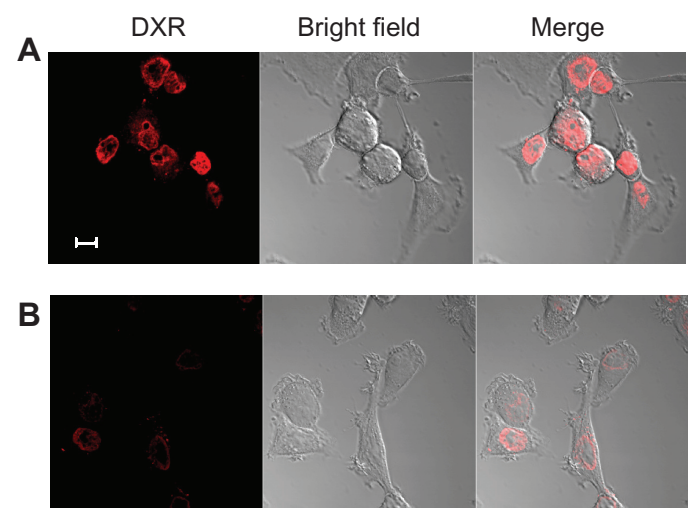

Figure 5 Confocal laser scanning microscopy image of $K B$ cells incubated with F-PLL-coated liposomal DXR for 3 hours at $37^{\circ} \mathrm{C}(\mathbf{A})$ without or (B) with $5 \mathrm{mM}$ FA in culture medium.

Note: The scale bar represents $10 \mu \mathrm{m}$.

Abbreviations: DXR, doxorubicin; FA, folic acid; F-PLL, folate-poly(L-lysine).

folate-coated liposomes had no PEG linker and a highly positive charge, the cellular association of liposomes via FR was observed. With regard to the linker between the polymer and folate in liposomes modified with folate-PEG-lipid, Lee and Low ${ }^{15}$ demonstrated that the effective PEG chain length in folate-PEG-modified liposomes on FR-mediated endocytosis was at least $25 \mathrm{~nm}$. We also reported that folate conjugated with a shorter PEG-length lipid with reduced folate exposure from liposomes to FRs, ${ }^{18}$ and folate-lipid (direct folate conjugate to lipid)-modified microemulsion showed a low level of association with KB cells, similar to nonfolate-modified microemulsions. ${ }^{36}$

With regard to the surface charge of liposomes, we reported that cellular association of folate-PEG-modified liposomes with $-20.2 \mathrm{mV}$, was saturated after 2-3-hour incubations. ${ }^{18}$ In this study, F-PLL-coated liposomes with a positive charge were taken up progressively and were not saturated within a 3-hour incubation (data not shown).

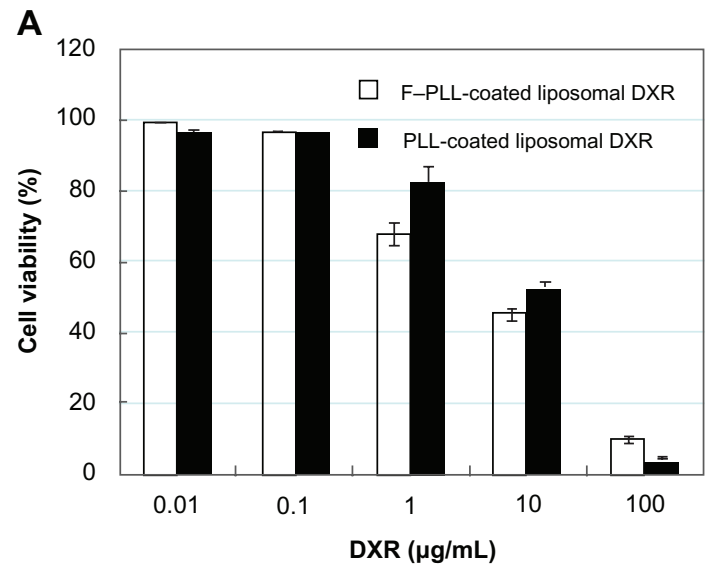

Table $2 \mathrm{IC}_{50}$ of DXR solution, F-PLL- and PLL-coated liposomal DXR against $K B$ cells or $A 549$ cells at 48 hours

\begin{tabular}{lcc}
\hline Formulation & \multicolumn{1}{l}{$\mathbf{C}_{50}(\mu \mathrm{M})$} & \\
\cline { 2 - 3 } & $\mathbf{K B}$ cells & $\mathbf{A 5 4 9}$ cells \\
\hline DXR solution & 1.20 & 2.17 \\
F-PLL-coated liposomal DXR & 30.75 & 104.31 \\
PLL-coated liposomal DXR & 64.97 & 105.71 \\
\hline
\end{tabular}

Abbreviations: DXR, doxorubicin; F-PLL, folate-poly(L-lysine).

In folate-modified positively charged lipoplexes, inhibition of cellular uptake by FA was hardly observed.$^{37}$ However, in this study, folate-modified, positively charged, polymer-coating particles exhibited inhibition of cellular uptake by FA. These findings suggested that F-PLL chains could cover the anionic liposomes loosely and partly protrude from the liposome surface because of fluctuations in the polymer chains.

Finally, cellular uptake of F-PLL-coated liposomal DXR was compared with folate-PEG modified liposomal DXR using folate-PEG-lipid. We previously reported two kinds of folate-PEG (molecular weight 5000) modified liposomal DXR: DXR loaded into liposomes via the $\mathrm{pH}$ gradient method $^{18}$ and the ionophore-mediated method. ${ }^{38}$ Cellular association of DXR of F-PLL-coated liposome with $6.9 \mathrm{~mol} \%$ folate modification was similar with both folate-PEG modified liposomes with 0.03 or $0.25 \mathrm{~mol} \%$ folate modification that was optimized, through flow cytometry analysis after incubation with $\mathrm{KB}$ cells for 1 hour at $37^{\circ} \mathrm{C}$. Cytotoxicity of F-PLL-coated liposomal DXR $\left(\mathrm{IC}_{50}=30.75 \mu \mathrm{M}\right)$ was similar to folate-PEG modified liposomal DXR loaded by the ionophore-mediated method, ${ }^{38}$ but was approximately 15 fold lower than that via the $\mathrm{pH}$ gradient method. ${ }^{18}$ It may be related to the release of DXR being different between the two loading methods in terms of the liposomes. From these findings, it is suggested that the release of DXR from

B

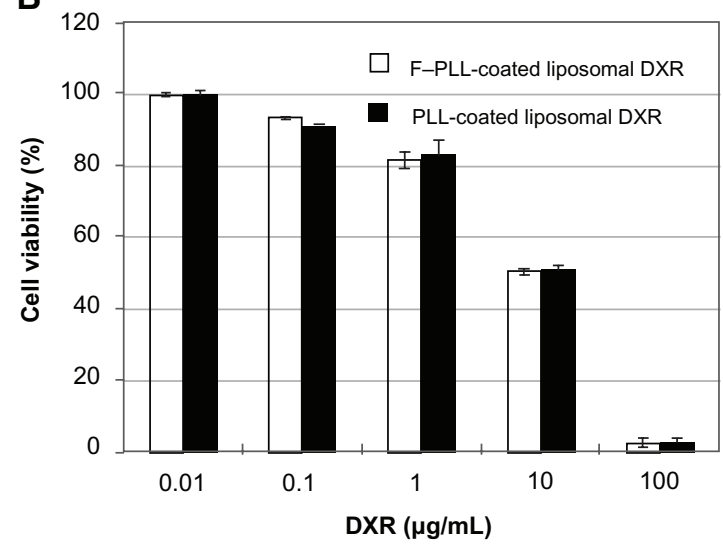

Figure 6 Cytotoxicity of F-PLL-coated liposomal DXR or PLL-coated liposomal DXR against (A) KB cells and (B) A549 cells.

Notes: Cells were incubated with liposomes in folate-free medium for 2 hours, then in fresh medium without the drug for 48 hours at $37^{\circ} \mathrm{C}$. Data indicate the mean \pm SD ( $n=6$ ). Abbreviations: DXR, doxorubicin; F-PLL, folate-poly(L-lysine). 
F-PLL-coated liposomes may be low after cellular uptake through the coating of the F-PLL, although DXR was loaded into the F-PLL-coated liposome via the $\mathrm{pH}$ gradient method. In future, optimization of the folate conjugation of PLL and enhancement of the release of liposomal drugs such as $\mathrm{pH}-$ sensitive liposomes will be needed.

\section{Conclusions}

In this study, the first liposome-based, tumor-targeting nanodevice has been prepared using a ligand-conjugated, polymer-coating technique. The cellular association of the F-PLL-conjugate-coated liposomes was 1.5-fold higher, depending on an approximately 1.5 -fold increase in folate modification. The KB cellular association of F-PLL-coated liposomes was increased compared with that of PLL-coated liposomes, which was inhibited by free FA. The cytotoxicity of F-PLL-coated liposomal DXR in KB cells was twofold higher than that of PLL-coated liposomal DXR, suggesting the presence of folate receptor-mediated endocytosis. Consequently, the folate ligand led to the association of liposomes with KB cells. Thus, F-PLL-coated liposomes are expected to constitute a new tumor-targeting nanodevice. This novel preparation method of folate-targeted liposomes is expected to form a powerful tool to develop folate-targeting drug nanodevices because coating with ligand-polymer conjugates may be applicable to many kinds of particles in addition to lipid-based particles.

\section{Acknowledgments}

We are grateful to Drs Masayuki Yokoyama and Kouichi Shiraishi of The Jikei University for advice on chemical synthesis and NMR measurements. This work was supported in part by the Science Research Promotion Fund by the Promotion and Mutual Aid Corporation for Private Schools of Japan.

\section{Disclosure}

The authors report no conflicts of interest in this work.

\section{References}

1. Weitman SD, Lark RH, Coney LR, et al. Distribution of the folate receptor GP38 in normal and malignant cell lines and tissues. Cancer Res. 1992;52(12):3396-3401.

2. Ross JF, Chaudhuri PK, Ratnam M. Differential regulation of folate receptor isoforms in normal and malignant tissues in vivo and in established cell lines. Physiologic and clinical implications. Cancer. 1994;73(9):2432-2443.

3. Toffoli G, Cernigoi C, Russo A, Gallo A, Bagnoli M, Boiocchi M. Overexpression of folate binding protein in ovarian cancers. Int J Cancer. 1997;74(2):193-198.
4. Wu M, Gunning W, Ratnam M. Expression of folate receptor type alpha in relation to cell type, malignancy, and differentiation in ovary, uterus, and cervix. Cancer Epidemiol Biomarkers Prev. 1999;8(9):775-782.

5. Elnakat H, Ratnam M. Distribution, functionality and gene regulation of folate receptor isoforms: implications in targeted therapy. Adv Drug Deliv Rev. 2004;56(8):1067-1084.

6. Parker N, Turk MJ, Westrick E, Lewis JD, Low PS, Leamon CP. Folate receptor expression in carcinomas and normal tissues determined by a quantitative radioligand binding assay. Anal Biochem. 2005; 338(2):284-293.

7. Guo W, Lee RJ. Targeted gene delivery via the folate receptor. Controlled Drug Delivery, ACS Symposium Series. 2000;752:212-219.

8. Ward CM, Pechar M, Oupicky D, Ulbrich K, Seymour LW. Modification of pLL/DNA complexes with a multivalent hydrophilic polymer permits folate-mediated targeting in vitro and prolonged plasma circulation in vivo. J Gene Med. 2002;4(5):536-547.

9. Kim SH, Jeong JH, Cho KC, Kim SW, Park TG. Target-specific gene silencing by siRNA plasmid DNA complexed with folate-modified poly(ethylenimine). J Control Release. 2005;104(1):223-232.

10. Hayama A, Yamamoto T, Yokoyama M, Kawano K, Hattori Y, Maitani Y. Polymeric micelles modified by folate-PEG-lipid for targeted drug delivery to cancer cells in vitro. J Nanosci Nanotechnol. 2008;8(6):3085-3090.

11. Bae Y, Kataoka K. Intelligent polymeric micelles from functional poly(ethylene glycol)-poly(amino acid) block copolymers. Adv Drug Deliv Rev. 2009;61(10):768-784.

12. Lu T, Sun J, Chen X, Zhang P, Jing X. Folate-conjugated micelles and their folate-receptor-mediated endocytosis. Macromol Biosci. 2009; 9(11):1059-1068.

13. Nie Y, Zhang Z, Li L, Luo K, Ding H, Gu Z. Synthesis, characterization and transfection of a novel folate-targeted multipolymeric nanoparticles for gene delivery. J Mater Sci Mater Med. 2009;20(9):1849-1857.

14. Patra CR, Bhattacharya R, Mukherjee P. Fabrication and functional characterization of goldnanoconjugates for potential application in ovarian cancer. J Mater Chem. 2010;20(3):547-554.

15. Lee RJ, Low PS. Delivery of liposomes into cultured KB cells via folate receptor-mediated endocytosis. J Biol Chem. 1994;269(5):3198-3204.

16. Lee RJ, Low PS. Folate-mediated tumor cell targeting of liposomeentrapped doxorubicin in vitro. Biochim Biophys Acta. 1995;1233(2): 134-144.

17. Gabizon A, Horowitz AT, Goren D, et al. Targeting folate receptor with folate linked to extremities of poly(ethylene glycol)-grafted liposomes: in vitro studies. Bioconjug Chem. 1999;10(2):289-298.

18. Yamada A, Taniguchi Y, Kawano K, Honda T, Hattori Y, Maitani Y. Design of folate-linked liposomal doxorubicin to its antitumor effect in mice. Clin Cancer Res. 2008;14(24):8161-8168.

19. Kawano K, Onose E, Hattori Y, Maitani Y. Higher liposomal membrane fluidity enhances the in vitro antitumor activity of folate-targeted liposomal mitoxantrone. Mol Pharm. 2009;6(1):98-104.

20. Needham D, McIntosh TJ, Lasic DD. Repulsive interactions and mechanical stability of polymer-grafted lipid membranes. Biochim Biophys Acta. 1992;1108(1):40-48.

21. Blume G, Cevc G. Molecular mechanism of the lipid vesicle longevity in vivo. Biochim Biophys Acta. 1993;1146(2):157-168.

22. Unezaki S, Maruyama K, Takahashi N, et al. Enhanced delivery and antitumor activity of doxorubicin using long-circulating thermosensitive liposomes containing amphipathic polyethylene glycol in combination with local hyperthermia. Pharm Res. 1994;11(8): $1180-1185$.

23. Maeda H, Wu J, Sawa T, Matsumura Y, Hori K. Tumor vascular permeability and the EPR effect in macromolecular therapeutics: a review. J Control Release. 2000;65(1-2):271-284.

24. Fang J, Sawa T, Maeda H. Factors and mechanism of "EPR" effect and the enhanced antitumor effects of macromolecular drugs including SMANCS. Polymer Drugs in the Clinical Stage, Adv Exp Med Biol. 2004;519:29-49. 
25. Greish K. Enhanced permeability and retention of macromolecular drugs in solid tumors: a royal gate for targeted anticancer nanomedicines. J Drug Target. 2007;15(7-8):457-464.

26. Mishra S, Webster P, Davis ME. PEGylation significantly affects cellular uptake and intracellular trafficking of non-viral gene delivery particles. Eur J Cell Biol. 2004;83(3):97-111.

27. Laverman P, Carstens MG, Boerman OC, et al. Factors affecting the accelerated blood clearance of polyethylene glycol-liposomes upon repeated injection. J Pharmacol Exp Ther. 2001;298(2):607-612.

28. Ishida T, Ichikawa T, Ichihara M, Sadzuka Y, Kiwada H. Effect of the physicochemical properties of initially injected liposomes on the clearance of subsequently injected PEGylated liposomes in mice. J Control Release. 2004;95(3):403-412.

29. Ishida $T$, Ichihara $M$, Wang $X$, et al. Injection of PEGylated liposomes in rats elicits PEG-specific IgM, which is responsible for rapid elimination of a second dose of PEGylated liposomes. J Control Release. 2006;112(1):15-25.

30. Ishida T, Wang X, Shimizu T, Nawata K, Kiwada H. PEGylated liposomes elicit an anti-PEG IgM response in a T cell-independent manner. J Control Release. 2007;122(3):349-355.

31. Takeuchi H, Kojima H, Toyoda T, Yamamoto H, Hino T, Kawashima Y. Prolonged circulation time of doxorubicin-loaded liposomes coated with a modified polyvinyl alcohol after intravenous injection in rats Eur J Pharm Biopharm. 1999;48(2):123-129.
32. Takeuchi H, Kojima H, Yamamoto H, Kawashima Y. Passive targeting of doxorubicin with polymer coated liposomes in tumor bearing rats. Biol Pharm Bull. 2001;24(7):795-799.

33. Fukui Y, Fujimoto K. The preparation of sugar polymer-coated nanocapsules by the layer-by-layer deposition on the liposome. Langmuir. 2009;25(17):10020-10025.

34. Lee RJ, Low PS. Folate as a targeting device for proteins utilizing folate receptor-mediated endocytosis. Drug Targeting, Methods $\mathrm{Mol} \mathrm{Med}$. 2000;25:69-76.

35. Wang S, Lee RJ, Mathias CJ, Green MA, Low PS. Synthesis, purification, and tumor cell uptake of ${ }^{67} \mathrm{Ga}$-deferoxamine-folate, a potential radiopharmaceutical for tumor imaging. Bioconjug Chem. 1996;7(1):56-62.

36. Shiokawa T, Hattori Y, Kawano K, et al. Effect of polyethylene glycol linker chain length of folate-linked microemulsions loading aclacinomycin A on targeting ability and antitumor effect in vitro and in vivo. Clin Cancer Res. 2005;11(5):2018-2025.

37. Hattori Y, Maitani Y. Folate-linked nanoparticle-mediated suicide gene therapy in human prostate cancer and nasopharyngeal cancer with herpes simplex virus thymidine kinase. Cancer Gene Ther. 2005;12(10):796-809.

38. Kawano K, Maitani Y. Effects of polyethylene glycol spacer length and ligand density on folate receptor targeting of liposomal doxorubicin in vitro. J Drug Deliv. 2011:160967. 


\section{Supplementary figures}



Figure SI UV spectra of F-PLL, FA, and PLL solutions.

Abbreviations: FA, folic acid; F-PLL, folate-poly(L-lysine).

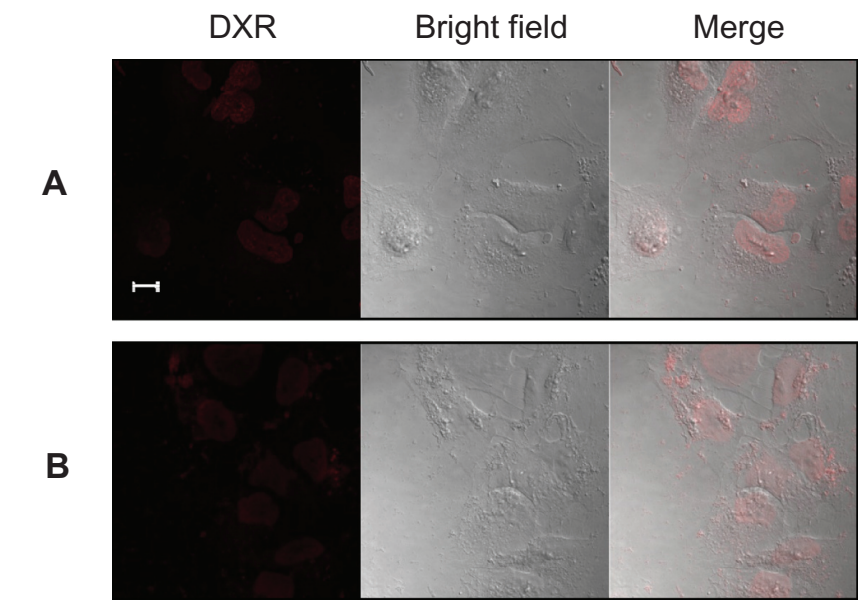

Figure S2 Confocal laser scanning microscopy image of A549 cells incubated with F-PLL-coated liposomal DXR for 3 hours at $37^{\circ} \mathrm{C}(\mathbf{A})$ without or (B) with 5 mM FA in culture medium.

Note: The scale bar represents $10 \mu \mathrm{m}$.

Abbreviations: DXR, doxorubicin; FA, folic acid; F-PLL, folate-poly(L-lysine)

\section{Publish your work in this journal}

The International Journal of Nanomedicine is an international, peerreviewed journal focusing on the application of nanotechnology in diagnostics, therapeutics, and drug delivery systems throughout the biomedical field. This journal is indexed on PubMed Central, MedLine, CAS, SciSearch $\AA$, Current Contents $\AA /$ Clinical Medicine,
Journal Citation Reports/Science Edition, EMBase, Scopus and the Elsevier Bibliographic databases. The manuscript management system is completely online and includes a very quick and fair peer-review system, which is all easy to use. Visit http://www.dovepress.com/ testimonials.php to read real quotes from published authors. 